\title{
Where are Race, Ethnicity, and Culture in Personality Research?
}

\author{
Moin Syed \\ University of Minnesota
}

Version Date: February 5, 2021

This is a preprint submitted for review. Comments are most welcome.

This paper has not been peer reviewed or commented on by anyone.

Read and trust at your own risk.

Note: This paper was submitted via the Insights \& Ideas format at Personality Science, which includes restrictions on the word count and the number of references. Accordingly, some points are unelaborated, and there are no citations for many of the claims, for better or for worse.

An earlier version of this paper was presented at the UC Riverside, Department of Psychology Social/Personality Area Brown Bag in November 2020. Video, slides, and a script of that presentation are available at https://osf.io/cwpjq/. Comments, questions, and complaints can be sent to moin@umn.edu. 


\begin{abstract}
In recent years personality research has re-affirmed its status as what Revelle famously termed "the last refuge of the generalist." Conceptualizing personality as consisting of traits, characteristic adaptations, and life stories, all of which must be understood in the context of biological and cultural foundations, provides a "big tent" to integrate nearly any aspect of psychology. And yet, this big tent has seemingly had little room for scholarship focused on race, ethnicity, and culture. This paper includes a brief discussion of five reasons why this has been the case: a) overstating the universality of traits, b) overstating the genetic basis of personality, c) hyper-focusing on dispositions, d) a compromising association with social psychology, and e) a weak approach to examining group differences. The paper concludes with some ideas for constructing a bigger, more inclusive tent.
\end{abstract}

Keywords: personality, race, ethnicity, culture 
Revelle (2007) famously declared that personality research is "the last refuge of the generalist." Personality psychologists like to parrot this claim ${ }^{1}$, as it helps to succinctly establish the importance of the sub-discipline within the broader field. But how accurate is the claim? What does it mean to be a generalist, and what conditions are necessary for it to be so? In this paper I take up the issue specifically with respect to the role of race, ethnicity, and culture. I first make some comments on the history and current state of personality research, mostly to set up the second section, focused on reasons and solutions for the absence of race/ethnicity/culture in the field

\section{Some Brief Comments on the History and Current State of Personality Research}

The title of this paper is a play on Rae Carlson's (1971) classic article, "Where is the person in personality research?" Since Carlson's admonishment, the field has done a better job including the person, particularly with the emergence of narrative identity research (Dunlop et al., 2016), within-person variability (Fleeson \& Jayawickreme, 2015), and idiographic approaches (Beck \& Jackson, 2020). Collectively, these efforts re-capture some of the imagination and excitement around personality that were present in the early days of the field.

What accounts for this movement? One possibility is that it was encouraged by the near-extinction of personality research in the wake of the so-called "person by situation debate" (see Funder 2006). When personality research was gasping for air, it was in its best interest to be welcoming to different approaches and conceptualizations - to make room for all comers-as increasing the number of scholars identifying with personality would help keep it alive. Accordingly, rather than narrow the definition of personality, under severe threat the field broadened the definition-or more accurately it worked to keep the definition broad.

This comment may be surprising to some readers. Personality research is often thought of in terms of traits, and even more narrowly in terms of the Big Five traits. This seems to be especially the case for researchers outside of personality psychology, but even those within it will commonly equate personality with traits. This persistent problem notwithstanding, personality researchers have been broadly accepting of the three-level organizational system articulated by McAdams and Pals (2006):

Personality is conceived as an individual's unique variation on the general evolutionary design for human nature, expressed as a developing pattern of dispositional traits, characteristic adaptations, and self-defining life narratives, complexly and differentially situated in culture and social context. (p. 204)

In brief, personality can be organized into three levels: Level 1 Traits, which refer to relatively stable variations in individual differences; Level 2 Characteristic adaptation, which are contextualized patterns of responses to individual life circumstances that DeYoung (2015)

\footnotetext{
${ }^{1}$ I was trained primarily as a developmental psychologist, and it is interesting that I was repeatedly told the same thing about developmental research, so perhaps all sub-disciplines believe themselves to hold this status.
} 
further clarified can be thought of as consisting of goals, interpretations, and strategies; and Level 3, Integrative life narratives, or the stories that people tell about their personal past to make meaning and develop a sense of identity. Importantly, all three levels are situated within biological and cultural contexts, with traits being more proximal to biological foundations, integrative life narratives more proximal to culture, and characteristic adaptations sandwiched in between (Figure 1).

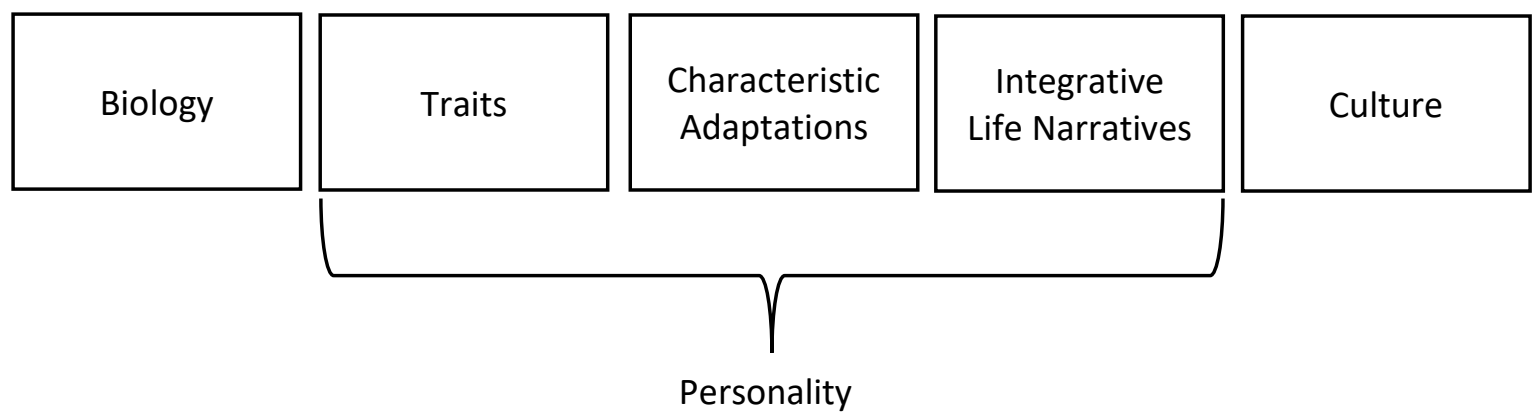

Figure 1. Visual representation of the McAdams and Pals (2006) organizational system for personality, showing that traits, characteristic adaptations, and integrative life narratives constitute the three levels of personality that exist within biological and cultural contexts. Proximity of the objects corresponds to greater connections between and among them.

This "big tent" approach to personality certainly helps communicate its broad relevance for psychological science. The three-level conceptualization is a useful organizational scheme, but it is not a scientific theory and thus does not provide guidance for how to integrate across the levels and the biological/cultural contexts. The connections you do see are largely within proximal levels on the biological side of the framework (e.g., behavior genetics and personality neuroscience focus heavily on traits, and to lesser extent characteristic adaptations). But what about the cultural side of the model? Where are race, ethnicity, and culture in all of this? Why is there no coherent field for personality and culture? If personality is the last refuge of the generalist, how has cultural psychology not been well-integrated into the field?

\section{The Place of Race/Ethnicity in Personality Research}

There is, of course, existing work on personality and culture (Benet-Martínez, 2012; Mendoza-Denton \& Worrell, 2019) but it is limited and of specific types. Indeed, it is necessary to recognize that there are many different types of cultural psychology (see Syed \& Kathawalla, 2018), but for now I will describe just three:

Cross-cultural psychology, arguably the most commonly used approach in personality trait research, is primarily drawn from a universalist perspective (see Shweder, 2000). The goals of cross-cultural psychology are often to document similarities and differences in psychological phenomena through a comparison of cultural (usually national) groups, with the ultimate goal of determining invariance (Segall et al, 1998). 
In contrast, what is often referred to as cultural psychology focuses on the local meaning of psychological phenomena, and how variations in mentalities around the world are associated with variations in psychological experience. Cultural psychology does not reject the possibility of universals, but tends to emphasize that whereas psychological processes are likely universal, their contents (i.e., manifestations) are not, and the contents can impact the processes (Shweder, 2000).

Finally, ethnic minority psychology is focused on the meaning and experience of being an ethnic minority within a specific national context (Hall et al., 2011). Accordingly, ethnic minority psychology tends to have a stronger focus on structural contexts, seeking to understand how power, oppression, and privilege contour psychological phenomena. This component is generally lacking in cross-cultural psychology and most forms of cultural psychology. Whereas cross-cultural and cultural psychology have been conducted by researchers around the world, ethnic minority psychology has focused heavily on the U.S. context, but has also been adopted in Canada, UK, Germany, Netherlands, and other countries.

In personality research we see some cross-cultural approaches, testing the generality of trait structures across national contexts, and we see some cultural approaches that focus on inductive and indigenous conceptualizations of personality. These two foci are evident in Cheung et al.'s (2011) "Toward a New Approach to the Study of Personality in Culture." The authors argue that although some use the cross-cultural approach (what they refer to as etic) and others use the cultural approach (emic), the most promising path forward combines the two, bridging the interests of universalism and cultural specificity, such as the South African Personality Inventory (Hill et al., 2013).

Two things about that paper. First, when they say "personality" they mean "traits," but as I indicated earlier, this is a common occurrence. More germane to the present discussion, however, is that there is nary a mention of race/ethnicity. A high-profile article on the future of research on personality and culture has literally nothing to say on the topic of race/ethnicity. The paper illustrates a broader point that is evident in the field: personality research has been generally open to cultural (or more accurately, national) variations in trait patterns, but much less open to examining the racial/ethnic context of personality, especially with respect to structural systems of power, oppression, and privilege. Instead, what we largely have is a crosscultural psychology of traits of the privileged. That does not seem like an ideal state for the last refuge of the generalist.

But why are we in this state? There is a thriving field of ethnic minority psychology, especially within developmental psychology, that is firmly engaging with personality at level 2 , characteristic adaptations, examining constructs such as identity, agency, resilience, empowerment, some of which is actually measured in rather trait-like ways. These folks are doing personality psychology, but very few-if any-would identify it as such. Why? I think there are several reasons, here I suggest five: 
Personality researchers are bullish on the universalism of trait structures. Perhaps this is a vestige of the person v. situation days, but it is not uncommon to see claims about the universality, or at least strong generalizability, of trait structures such as the Big Five. Certainly there is good evidence for that structure, but has there really been sufficient tests of generalizability? There are few quality papers directly comparing the Big Five across different racial/ethnic groups. Interestingly, personality trait researchers will assert the Big Five is generalizable, and ethnic minority researchers will assert it is not, but both of these assertions are absent strong data.

Personality researchers are bullish on the universalism of genetics. Perhaps this one is due to our old friend "physics envy," but the role of genetic variation for personality is widely overstated. There is certainly ample evidence among limited populations for the heritability of personality traits (i.e., the First Law of Behavior Genetics; Turkheimer, 2000), but because so many treat traits as equivalent to personality this set of findings gets extrapolated to ample evidence for the heritability of personality. Of course, ethnic minority psychologists have good reasons to be skeptical of shaky claims of the genetic bases of psychological phenomena (see Syed \& Kathawalla, 2018 for a discussion).

Personality research is overly dispositional. This is almost a tautological statement, as personality is often literally defined as dispositions. However, just because personality is about dispositions does not mean that personality research needs to be overly dispositional. I mentioned earlier that ethnic minority psychologists, especially developmentalists, are already doing personality research. But they are also doing more. They are including ideas and constructs that recognize the broader structural realities of minority youth, such as discrimination, cultural socializations, educational opportunity, segregation, and so on (see Neblett et al, 2012). High profile ideas rooted in personality psychology, such as grit-but even the more general form of conscientiousness-are embedded within the individualist, endless opportunity ethos of the U.S. context (manifestations of the American Dream master narrative; see Syed et al. (2018) for a discussion).

Personality research is compromised by its association with social psychology. This point is directly related to my previous. To the extent that the dispositionally-focused personality attends to the social context, it does so in alignment with it frenemy social psychology. Social psychology of course focuses on context, but it focuses on the micro-context, the situation. Generally speaking, as a field, it has not engaged deeply with the structural contexts that contour opportunity (see Oishi et al., 2009), which tends to be more of a focus of ethnic minority psychology. Thus, when thinking about context, personality turns to its proximal conceptualization of context, and not to a conceptualization that would be of interest to most researchers attending to race/ethnicity. Rather than aligning with social psychology, I agree strongly with Smith (2005) that personality has a more natural and potentially productive integration with developmental psychology, which is well integrated with ethnic minority psychology. 
Personality research is not well-equipped to study group variation. Research on personality traits tends to focus on patterns of individual differences, but less so on how those patterns vary by groups. Our neighbor social psychology of course studies groups, but more in terms of group relations and dynamics, and not so much on group differences. For a field that is otherwise methodologically sophisticated, the study of group variation is still handled in just about the weakest way possible. Let me illustrate.

The dominant approach to culture in personality and social psychology is Markus and Kitayama's (1991) independent vs. interdependent selves. This whole line of research is deeply flawed conceptually (read McSweeney, 2002), but for now I will just focus on the methodological approach. Matsumoto (1999) published an under-appreciated paper evaluating the claims made in Markus and Kitayama (1991). Matsumoto distilled the model as essentially arguing that cultural self-construals mediated the associations between cultural variations and psychological outcomes; that the reason for observed cultural variations in some psychological processes is because of cultural differences in some other psychological processes, namely the self-construals of independence vs. interdependence. As Matsumoto so astutely argued, the authors made a compelling case for the theory, drawing from disparate literatures in social, personality, and cognitive psychology. They convinced people then, and they continue to convince people today. And yet, remarkably, they did not provide a single piece of evidence that supported their asserted model. Rather than the studies testing cultural processes as mediating cultural differences, all of the evidence simply consisted of cross-national differences in psychological processes (Figure 2). Cultural processes were not measured. Self-construals were not measured. Nations were simply compared, and conclusions were drawn. Sadly, we could change the date on Matsumoto from 1999 to 2021. Nothing has changed with this supposed gold standard line of cultural personality research (e.g., Lee \& Ashton, 2020).

(a)

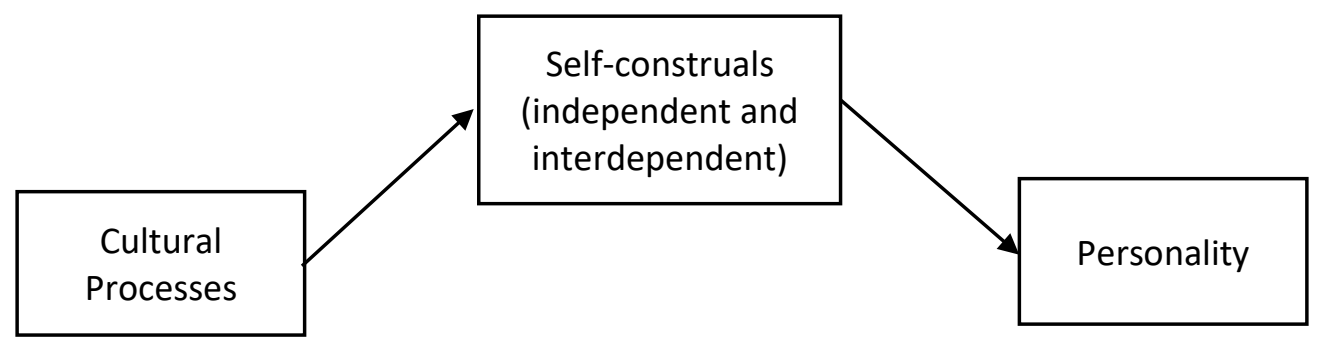

(b)

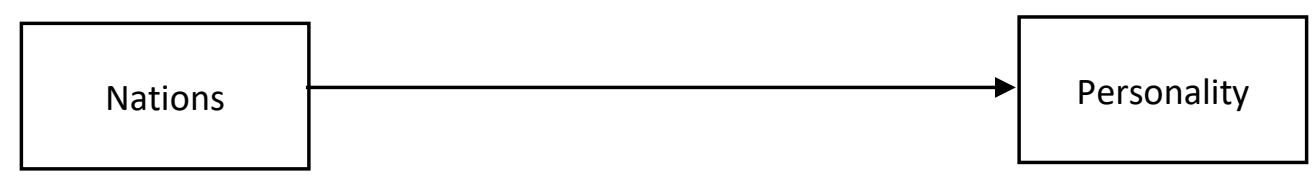

Figure 2. Model (a) illustrates the theoretical argument made by Markus \& Kitayama (1991), that variations in self-construals explain the link between variations in cultural processes and personality. Model (b) illustrates the evidence provided in support of that theoretical argument, which consists of observed national differences in personality. This figure is slightly modified from Matsumoto (1999).

Ethnic minority psychologists tend to be deeply skeptical of group comparative work a) in general, and b) that does not include an analysis of the putative mechanisms that account for 
the differences. Why? Because of the long history of psychology interpreting such differences from a deficit perspective, in which the dominant White group is held as the standard, and the minority groups represent deviations from that standard. Thus, it is important for folks engaging with this work to think about the reasons for why group differences might be observed (see Syed, 2020). Observed differences in psychological phenomena are never because of individuals' race/ethnicity, which have no causal power of their own, but because of some psychological variation that co-occurs with the groups. If the assertion is that traits are culturally expressed, and thus might vary due to the cultural differences, there needs to be some measure of how people align with those cultural expressions. Cultural expressions are individual differences, not inherent to groups. Taking this issue seriously is one of the major ways to move forward with a meaningful connection between personality and ethnic minority psychology.

Importantly, this solution is evident in the McAdams and Pals (2006) conceptualization of personality. Existing studies of group differences, many of which take the Markus and Kitayama (1991) approach, are attempting to connect culture to traits. However, if you recall my argument about the proximal nature of the different levels of personality, it may just be impossible to gain useful insights about cultural variations in traits without passing through the levels of characteristic adaptations and/or life stories (Figure 3). That is, traits are too distal from cultural contexts to be able to understand much about the culture nature of traits without consideration of the ways in which individuals engage with their cultures (represented by characteristic adaptations and life stories).

(a)
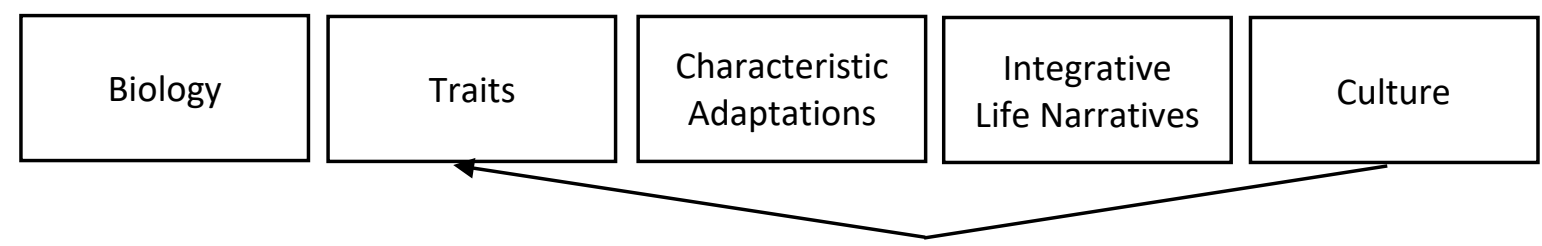

(b)
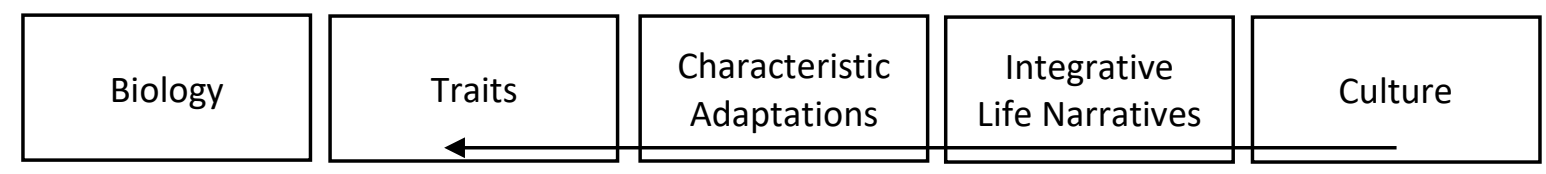

Figure 3. Panel (a) illustrates the typical approach to culture and personality, in which groups are compared on traits. Panel (b) illustrates a potentially more informative approach by understanding cultural variations in traits via the more proximal levels of integrative life narratives and characteristic adaptations. This figure shows the same two approaches as illustrated in Figure 2.

Those levels are the bread and butter of ethnic minority psychology, so serious engagement with them will lead towards a greater connection between these areas. And greater connection is needed, not only to live up to Revelle's claim that personality is the last refuge of the generalist, but also to address Carlson's long-ago question of where the person is in personality research. Personality research must consider all persons within the contexts of how their lives are lived. 


\section{References}

Beck, E. D., \& Jackson, J. J. (2020). Idiographic Traits: A Return to Allportian Approaches to Personality. Current Directions in Psychological Science, 29(3), 301-308. 10.1177/0963721420915860

Benet-Martínez, V. (2012). Multiculturalism: Cultural, social, and personality processes. In K. Deaux and M. Snyder (Eds.), The Oxford handbook of personality and social psychology, (pp. 623-648). Oxford University Press. 10.1093/oxfordhb/9780195398991.013.0025

Carlson, R. (1971). Where is the person in personality research? Psychological Bulletin, 75(3), 203-219. $10.1037 /$ h0030469

Cheung, F. M., van de Vijver, F. J. R., \& Leong, F. T. L. (2011). Toward a new approach to the study of personality in culture. American Psychologist, 66(7), 593-603. 10.1037/a0022389

DeYoung, C. G. (2015). Cybernetic Big Five Theory. Journal of Research in Personality, 56, 33-58. 10.1016/i.jrp.2014.07.004

Dunlop, W. L., Guo, J., \& McAdams, D. P. (2016). The autobiographical author through time: Examining the degree of stability and change in redemptive and contaminated personal narratives. Social Psychological and Personality Science, 7(5), 428-436. 10.1177/1948550616644654

Fleeson, W., \& Jayawickreme, E. (2015). Whole Trait Theory. Journal of Research in Personality, 56, 8292. 10.1016/j.jrp.2014.10.009

Funder, D. C. (2006). Towards a resolution of the personality triad: Persons, situations, and behaviors. Journal of Research in Personality, 40(1), 21-34. 10.1016/i.jrp.2005.08.003

Hall, G. C. N., Yip, T., \& Zárate, M. A. (2016). On becoming multicultural in a monocultural research world: A conceptual approach to studying ethnocultural diversity. American Psychologist, 71(1), 40-51. 10.1037/a0039734

Hill, C., Nel, J. A., Van de Vijver, F. J. R., Meiring, D., Valchev, V. H., Adams, B. G., \& De Bruin, G. P. (2013). Developing and testing items for the South African Personality Inventory (SAPI). SA Journal of Industrial Psychology, 39(1), 13 pages. 10.4102/saiip.v39i1.1122

Lee, K., \& Ashton, M. C. (2020). Sex differences in HEXACO personality characteristics across countries and ethnicities. Journal of Personality, 88(6), 1075-1090. 10.1111/iopy.12551

Markus, Hazel R., \& Kitayama, S. (1991). Culture and the self: Implications for cognition, emotion, and motivation. Psychological Review, 98(2), 224. 10.1037/0033-295X.98.2.224

Matsumoto, D. (1999). Culture and self: An empirical assessment of Markus and Kitayama's theory of independent and interdependent self-construals. Asian Journal of Social Psychology, 2(3), 289-310. 10.1111/1467-839X.00042

McAdams, D. P., \& Pals, J. L. (2006). A new Big Five: Fundamental principles for an integrative science of personality. American Psychologist, 61(3), 204-217. 10.1037/0003-066X.61.3.204 
McSweeney, B. (2002). Hofstede's Model of National Cultural Differences and their Consequences: A Triumph of Faith - a Failure of Analysis. Human Relations, 55(1), 89-118. $\underline{10.1177 / 0018726702551004}$

Mendoza-Denton, R., \& Worrell, F. C. (2019). Culture, race, ethnicity, and personality. In D. Cohen \& S. Kitayama (Eds.), Handbook of cultural psychology (p. 748-767). The Guilford Press.

Neblett Jr, E. W., Rivas-Drake, D., \& Umaña-Taylor, A. J. (2012). The promise of racial and ethnic protective factors in promoting ethnic minority youth development. Child Development Perspectives, 6(3), 295-303. 10.1111/j.1750-8606.2012.00239.x

Oishi, S., Kesebir, S., \& Snyder, B. H. (2009). Sociology: A Lost Connection in Social Psychology. Personality and Social Psychology Review, 13(4), 334-353. 10.1177/1088868309347835

Revelle, W. (2007). Experimental approaches to the study of personality. In Handbook of research methods in personality psychology (pp. 37-61). The Guilford Press.

Segall, M. H., Lonner, W. J., \& Berry, J. W. (1998). Cross-Cultural Psychology as a Scholarly Discipline. American Psychologist, 53(10), 1101-1110. 10.1037/0003-066X.53.10.1101

Shweder, R. A. (2000). The psychology of practice and the practice of the three psychologies. Asian Journal of Social Psychology, 3(3), 207-222. 10.1111/1467-839X.00065

Smith, M. B. (2005). "Personality and Social Psychology": Retrospections and Aspirations. Personality and Social Psychology Review, 9(4), 334-340. 10.1207/s15327957pspr0904 3

Syed, M. (2020). Whither the "White Control Group"? On the Benefits of a Comparative Ethnic Minority Psychology. PsyArXiv. 10.31234/osf.io/n4p73

Syed, M., \& Kathawalla, U. K. (2018). Integrating Culture and Biology in Psychological Research: Conceptual Clarifications and Recommendations. In J. M. Causadias, E. H. Telzer, \& N. A. Gonzales (Eds.), The Handbook of Culture and Biology (pp. 31-54). John Wiley \& Sons, Inc. 10.1002/9781119181361.ch2

Syed, M., Santos, C., Yoo, H. C., \& Juang, L. P. (2018). Invisibility of racial/ethnic minorities in developmental science: Implications for research and institutional practices. American Psychologist, 73(6), 812-826. 10.1037/amp0000294

Turkheimer, E. (2000). Three Laws of Behavior Genetics and What They Mean. Current Directions in Psychological Science, 9(5), 160-164. 10.1111/1467-8721.00084 